\title{
Slip event propagation direction in transition region of low surface slope
}

\author{
Johannes WEERTMAN \\ Department of Materials Science and Engineering, Department of Geological Sciences, Northwestern University, \\ Evanston, IL 60208, USA \\ E-mail: j-weertman2@northwestern.edu
}

\begin{abstract}
The base of the ice in the transition zone between an ice stream and an ice shelf is likely to be well lubricated by broadly distributed water, a condition which should permit fast sliding motion. It has been observed that motion takes place not smoothly but by localized stick-slip events that propagate in the downstream direction towards the ice shelf and at velocities approximately that expected for shear wave velocity of the basal till. Thus slip packets of gliding edge dislocations are likely to move at the base. I show here that subsonic dislocations should move upstream, rather than downstream, if frictional resistance is determined by normal traction stress change at the base. Transonic dislocations are expected to move in the downstream direction. However, if frictional resistance is lowered by hydrostatic pressure reduction at the base, the subsonic dislocation should move downstream.
\end{abstract}

\section{INTRODUCTION}

In the transition, ice-plain, region between Whillans Ice Stream and the Ross Ice Shelf and Crary Ice Rise, West Antarctica, the surface slope and basal shear stress is almost zero $(\approx 1 \mathrm{kPa})$ (Bindschadler and others, 2003a,b). The fast motion of the ice stream is transmitted through this region in a series of stick-slip events that propagate at a mean velocity of $88 \mathrm{~m} \mathrm{~s}^{-1}$ (Bindschadler and others, 2003a, b). Bindschadler and others observed that the transient motion events propagated downstream at a velocity of the order expected for a Stoneley wave traveling at the ice-basal-till interface or a shear wave traveling within the till. (Stoneley surface waves, which move on an interface at a velocity slightly slower than the lower shear wave velocity, do not produce slip across an interface. However, Stoneley waves should not exist at the ice-till interface. (See Equation (A4) of Appendix A.)) The magnitude of the total Burgers vector of the localized propagating dislocations must be at least $0.1 \mathrm{~m}$. Bindschadler and others $(2003 \mathrm{a}, \mathrm{b})$ show that the periodic ocean tides under the Ross Ice Shelf are in some way triggering the slip pulses. (Tides also influence icestream motion far inland (Anandakrishnan and Alley, 1997; Anandakrishnan and others, 2003).)

An ice plain of very low basal shear stress (100 times smaller than that of an active glacier) presents two problems. One is to account for the stick-slip motion (the primary concern of this paper). The other is to account for the existence of the low basal shear stress. The latter problem suggests either the basal till is very weak (a possibility ignored here) or the effective friction at the till-ice interface is small. I have argued the basal water in a transition region should be broadly, but not uniformly, distributed (see Appendix B and Weertman, 2003). The downstream pressure gradient in the basal water is 100 times smaller than in glaciers. Hence the average basal water thickness is at least 100 times larger than under a glacier, and the effective basal friction should therefore be at least 100 times smaller than under a glacier. Consider next the stick-slip problem.

Ice motion in the direction from an ice stream to an ice shelf is produced when positive glide edge dislocations at the ice-till interface move downstream or negative dislocations move upstream. The former produces downstream-propagating transient motion events, and the latter upstream-propagating transient motion events. (The dislocations treated here are not crystal dislocations but are gradients in displacement. That is, the dislocation density $B(x)$ of a smeared-out localized group of dislocations at an interface that move in the $x$ direction is equal (identical) to $-\mathrm{d} D / \mathrm{d} x$ where $D(x)$ is the displacement across the interface at $x$. If the displacement is a step function, the step height is the Burgers vector usually associated with a crystal dislocation.) A localized slip pulse that travels downstream at a till-ice interface is a localized distribution of moving dislocations, all of the same sign. Where the dislocations exist, the normal pressure across the interface is increased or decreased depending on the sign of the dislocations. A decrease in normal pressure presumably facilitates slip by decreasing the friction stress when the slip rate is too fast to be accounted for by ordinary, relatively slow glacier sliding mechanisms. In the next section, the interface traction stresses arising from a dislocation distribution of gliding edge dislocations which move at a velocity $V$ are presented.

\section{DISLOCATION SOLUTION}

Consider a smeared-out localized group of gliding edge dislocations of distribution density $B_{x}(x)$, shown schematically in Figure 1, on an interface between two media $A$ and $B$. The dislocations move at constant velocity $V$ in the $x$ direction. The shear constants of the media are $G_{A}$ and $G_{B}$, the densities are $\rho_{A}$ and $\rho_{B}$ and Poisson's ratios are $\nu_{A}$ and $\nu_{B}$. The shear wave speeds in the two media are equal to $C_{S A}=\sqrt{G_{A} / \rho_{A}}$ and $C_{S B}=\sqrt{G_{B} / \rho_{B}}$; the longitudinal wave

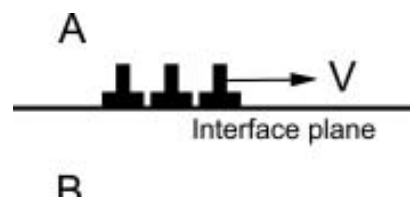

Fig. 1. Group of gliding edge dislocations. 


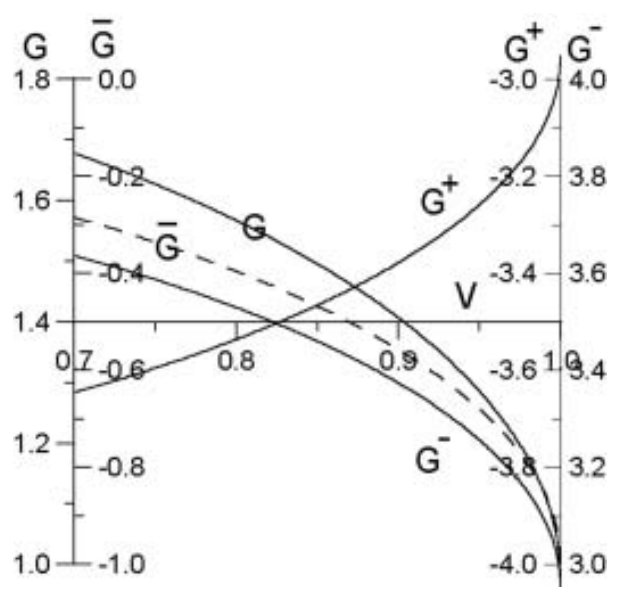

Fig. 2. Normalized plots of $G, \bar{G}, G^{+}$and $G^{-}$, vs $V$.

speeds are $C_{\mathrm{L} A}=C_{\mathrm{S} A} \sqrt{2\left(1-\nu_{A}\right) /\left(1-2 \nu_{A}\right)}$ and $C_{\mathrm{L} B}=$ $C_{S B} \sqrt{2\left(1-\nu_{B}\right) /\left(1-2 \nu_{B}\right)}$. The traction stresses on an interface produced by the dislocation distribution $B_{x}$ are given by the Comninou-Dundurs-type equations (Weertman 1980, 1996, 2004):

$$
\sigma_{y y}(x)=\bar{G} B_{x}(x), \quad \sigma_{x y}(x)=\frac{G}{\pi} \int_{-\infty}^{\infty} \frac{B_{x}\left(x^{\prime}\right) \mathrm{d} x^{\prime}}{x-x^{\prime}} .
$$

The non-traction stress $\sigma_{x x}$, which usually is of opposite sign but in general is not the same magnitude on either side of the interface, is given by

$$
\sigma_{x x}(x)=\left\{G^{+} B_{x}(x), \quad G^{-} B_{x}(x)\right\} .
$$

Here $G^{+}$and $G^{-}$refer respectively to the ice and till side of the interface. Expressions for the elastic-constant-type terms $G, \bar{G}, G^{+}$and $G^{-}$are given in Appendix A.

Figure 2 shows a normalized plot of $G / G_{B}, \bar{G} / G_{B}$, $G^{+} / G_{B}$, and $G^{-} / G_{B}$ vs $V / C_{S B}$, where $G_{B}$ is the shear modulus estimated for till, and $C_{S B}$ the shear velocity of the till (see Appendix A and the constants in Table 2). $G, \bar{G}, G^{+}$ and $G^{-}$are finite at $V=C_{S B}$. Note in Figure 2 that the normal stress $\sigma_{y y}(\bar{G})$ is negative (compressive). The signs of the stresses are reversed for negative gliding edge dislocation. $\bar{G}$ is negative in Figure 2. Consquently, the normal pressure is increased. If the frictional resistance to sliding is increased by increased normal pressure, the Figure 2 data imply that a positive gliding edge dislocation packet moves with greater difficulty, and a negative gliding edge dislocation packet moves with greater ease. The change in hydrostatic pressure $\Delta P$ in the till just beneath the dislocations is equal to $\Delta P=(-1 / 3)\left(\sigma_{x x}+\sigma_{y y}+\sigma_{z z}\right)=$ $(-1 / 3)\left(1+v_{B}\right)\left(\bar{G}+G^{-}\right) B_{x}$. From Figure 2 the hydrostatic pressure is reduced in the till.

When a Stoneley wave exists, the terms $G, \bar{G}$, etc., in a Figure 2 type plot become infinite at a velocity somewhat
Table 1. Transonic dislocation

\begin{tabular}{llll}
\hline$G / G_{B}$ & $\bar{G} / G_{B}$ & $G^{+} / G_{B}$ & $G^{-} / G_{B}$ \\
\hline 1.789 & 83.25 & 118.06 & 87.08 \\
\hline
\end{tabular}

smaller than the Stoneley wave velocity, which itself is slightly smaller than the slower shear wave velocity (Weertman, 2004). This is not seen in Figure 2, and therefore a Stoneley wave does not exist.

\section{TRANSONIC DISLOCATION}

A gliding edge dislocation moving at the generalized Eshelby velocity $V_{\mathrm{E}}$ (Weertman, 2002) has traction and non-traction stresses at the interface given by Equations (1) and (2), but with the $G$ terms given by Equations (A5) and (A6) of Appendix A. The Eshelby velocity, when it exists, is larger than the smaller shear wave velocity but smaller than the longitudinal wave velocities. Thus the velocity $V_{E}$ is transonic because it lies between the slowest and fastest sound velocities. At $V=V_{\mathrm{E}}$ the dislocation acts like a subsonic dislocation because it does not generate the shock waves that occur at transonic velocities when $V \neq V_{\mathrm{E}}$.

Table 1 lists the normalized values of the terms $G, \bar{G}, G^{+}$ and $G^{-}$found, using constants listed in Table 2, for a dislocation moving at the generalized Eshelby velocity. From Equation (A7) and the Table 2 constants: $V_{E}=9.253 V_{S B}=$ $0.816 V_{\mathrm{L} B}$. (When the two half-spaces are identical, the Eshelby velocity is equal to $V_{\mathrm{E}}=\sqrt{2} V_{\mathrm{S}}$.)

\section{DISCUSSION}

Bindschadler and others $(2003 a, b)$ have shown that ice motion propagates down the ice plain in front of Whillans Ice Stream in short time movements of the order of $0.1 \mathrm{~m}$ with a propagation velocity of the order expected for the shear velocity in the underlying till. Such motion strongly implies the motion of smeared subsonic gliding edge dislocation packets at the ice-till interface. (Of course, it also could be explained by deformation within the till.) Subsonic edge glide dislocations that move in the downstream direction produce increased normal pressure across the interface but decreased hydrostatic pressure in the till next to the interface. An increase in normal pressure usually is associated with increased friction and more difficult slip. On the other hand, if the hydrostatic pressure is lowered, a small amount of water flow from the till to the interface could occur rapidly and temporarily reduce, where the dislocations are, the resistance to interface slip. This is an attractive explanation of the downstream motion of the dislocations. The water flow

\begin{tabular}{|c|c|c|c|c|c|c|c|c|c|}
\hline$G_{A}$ & $G_{B}$ & $\rho_{A}$ & $\rho_{B}$ & $\nu_{A}$ & $\nu_{B}$ & $C_{\mathrm{S} A}$ & $C_{S B}$ & $C_{\mathrm{LA}}$ & $C_{\mathrm{L} B}$ \\
\hline GPa & GPa & $\mathrm{kg} \mathrm{m}^{-3}$ & $\mathrm{~kg} \mathrm{~m}^{-3}$ & & & $\mathrm{~ms}^{-1}$ & $\mathrm{~ms}^{-1}$ & $\mathrm{~ms}^{-1}$ & $\mathrm{~m} \mathrm{~s}^{-1}$ \\
\hline 3.7 & 0.0414 & 920 & 1840 & 0.33 & 0.496 & 2005.4 & 150 & 3981.3 & 1700 \\
\hline
\end{tabular}

Table 2. Constants $(A \rightarrow$ ice, $B \rightarrow$ till $)$ 
from the till is expected to be facilitated for the following reason. The deviatoric stress $\sigma_{\mathrm{D}}=(1 / 2)\left(\sigma_{x x}-\sigma_{y y}\right)$ within the till is approximately equal to $2 G_{B} B_{x}$ (from Equations (1) and (2) and Fig. 2) Here $B_{x} \approx$ slip distance $(\approx 0.1 \mathrm{~m})$ divided by width of the slip pulse. Thus $\sigma_{\mathrm{D}}=800,80,8 \mathrm{kPa}$ respectively for slip widths of $10,100,1000 \mathrm{~m}$. The strength of basal till under the West Antarctic ice streams seems to be of the order of $2-5 \mathrm{kPa}$ (Kamb, 2001). Thus, any pulse width smaller than about $2-4 \mathrm{~km}$ will cause breakdown of till.

From Table 1 it is seen that if a dislocation moves at the generalized Eshelby velocity, the normal pressure $\left(-\bar{G} B_{x}\right)$ across the interface as well as the hydrostatic pressure $\left((-1 / 3)\left(1+\nu_{B}\right)\left(\bar{G}+G^{-}\right) B_{x}\right)$ is reduced. Both conditions favor downstream dislocation motion. A dislocation that moves with this velocity (close to the longitudinal wave velocity of the till), of course, moves too quickly to explain the field observations. A transonic glide edge dislocation which moves with a speed close to but faster than the till shear wave velocity, and in the process radiates seismic energy into the till, might also have reduced normal and hydrostatic pressure at the interface.

\section{ACKNOWLEDGEMENTS}

I appreciate the helpful suggestions of an anonymous reviewer, T. Pfeiffer and S. Tulaczyk for improving the paper.

\section{REFERENCES}

Achenbach, J. 1973. Wave propagation in elastic solids. Amsterdam, North-Holland.

Anandakrishnan, S. and R.B. Alley. 1997. Tidal forcing of basal seismicity of Ice Stream C, West Antarctica, observed far inland. J. Geophys. Res. - Solid Earth, 102(B7), 15,183-15,196.

Anandakrishnan, S., D.E. Voigt, R.B. Alley and M.A. King. 2003. Ice Stream $D$ flow speed is strongly modulated by the tide beneath the Ross Ice Shelf. Geophys. Res. Lett., 30(7), 1361. (10.1029/ 2002GL016329.)

Bindschadler, R.A., M.A. King, R.B. Alley, S. Anandakrishnan and L. Padman. 2003a. Tidally controlled stick-slip discharge of a West Antarctic ice stream. Science, 301(5636), 1087-1089.

Bindschadler, R.A., P.L. Vornberger, M.A. King and L. Padman. 2003b. Tidally-driven stick-slip motion in the mouth of Whillans Ice Stream, Antarctica. Ann. Glaciol., 36, 263-272.

Blankenship, D.D., C.R. Bentley, S.T. Rooney and R.B. Alley. 1987. Till beneath Ice Stream B. 1. Properties derived from seismic travel times. J. Geophys. Res., 92(B9), 8903-8911.

Hobbs, P.V. 1974. Ice physics. Oxford, Clarendon Press.

Kamb, B. 2001. Basal zone of the West Antarctic ice streams and its role in lubrication of their rapid motion. In Alley, R.B. and R.A. Bindschadler, eds. The West Antarctic ice sheet: behavior and environment. Washington, DC, American Geophysical Union, 157-199.

Weertman, J. 1972. General theory of water flow at the base of a glacier or ice sheet. Rev. Geophys. Space Phys., 10(1), 287-333.

Weertman, J. 1980. Unstable slippage across a fault that separates elastic media of different elastic-constants. J. Geophys. Res., 85(NB3), 1455-1461.

Weertman, J. 1996. Dislocation based fracture mechanics. Singapore, World Scientific.

Weertman, J. 2002. Subsonic type earthquake dislocation moving at approximately root $2 \times$ shear wave velocity on interface between half spaces of slightly different elastic constants. Geophys. Res. Lett., 29(10). (10.1029/2001GL013916.)

Weertman, J. 2003. Why do ice streams have fast velocities in transition region of low surface slope? EOS Trans. AGU., 84(46), Fall Meet. Suppl., Abstract C22A-02.

Weertman, J. 2004. Quasidislocation Stoneley wave and Eshelby dislocation Scholte wave. Phys. Rev. Lett., 93(20), 205,505-205,509.

\section{APPENDIX A}

\section{TERMS $G$ AND $\bar{G}$}

The terms $G$ and $\bar{G}$ of Equation (1) and $G^{+}$and $G^{-}$of Equation (2) are equal to

$$
\begin{aligned}
G & =2\left(G_{A} / b_{x}\right)\left(b_{\mathrm{SA}} \beta_{\mathrm{SA}}^{-1} \beta_{2 \mathrm{SA}}^{2}+b_{\mathrm{LA}} \beta_{\mathrm{LA}}\right) \\
& =2\left(G_{B} / b_{x}\right)\left(b_{\mathrm{SB}} \beta_{\mathrm{SB}}^{-1} \beta_{2 S B}^{2}+b_{\mathrm{LB}} \beta_{\mathrm{LB}}\right), \\
\bar{G} & =2\left(G_{A} / b_{x}\right)\left(b_{\mathrm{SA}}+b_{\mathrm{LA}} \beta_{2 S A}^{2}\right) \\
& =-2\left(G_{B} / b_{x}\right)\left(b_{\mathrm{S} B}+b_{\mathrm{LB}} \beta_{2 S B}^{2}\right), \\
G^{+} & =-2\left(G_{A} / b_{x}\right)\left[b_{\mathrm{SA}}+b_{\mathrm{LA}}\left(2 \beta_{2 \mathrm{LA}}^{2}-\beta_{2 \mathrm{SA}}^{2}\right)\right], \\
G^{-} & =2\left(G_{B} / b_{x}\right)\left[b_{S B}+b_{\mathrm{LB}}\left(2 \beta_{2 \mathrm{LB}}^{2}-\beta_{2 S B}^{2}\right)\right] .
\end{aligned}
$$

Here

$$
\begin{aligned}
B_{S k} & =\sqrt{1-V^{2} / C_{S k}}, \\
B_{\mathrm{Lk}} & =\sqrt{1-V^{2} / C_{\mathrm{Lk}}}, \\
\beta_{2 S k} & =\sqrt{1-V^{2} / 2 C_{S k}}, \\
\beta_{2 \mathrm{Lk}} & =\sqrt{1-V^{2} / 2 C_{\mathrm{Lk}}},
\end{aligned}
$$

where $k=A$ or $B$ and $b_{x}$ is the Burgers vector of a discrete gliding dislocation. The sub-dislocation Burgers vectors are equal to

$$
\begin{aligned}
b_{\mathrm{SA}}= & b_{x} \frac{D_{1}\left(A_{5} A_{2}+A_{6} A_{3}\right)+D_{2}\left(A_{5} A_{1}-A_{6} A_{4}\right)}{D_{3}^{2}\left(A_{1} A_{3}+A_{4} A_{2}\right)} \\
& +b_{x} \frac{D_{3}\left(A_{1} A_{3}+A_{4} A_{2}\right)}{D_{3}^{2}\left(A_{1} A_{3}+A_{4} A_{2}\right)} \\
b_{\mathrm{LA}}= & -b_{x} \frac{A_{5} A_{2}+A_{6} A_{3}}{D_{3}\left(A_{1} A_{3}+A_{4} A_{2}\right)} \\
b_{\mathrm{LB}}= & -b_{x} \frac{A_{5} A_{1}-A_{6} A_{4}}{D_{3}\left(A_{1} A_{3}+A_{4} A_{2}\right)} \\
b_{S B}= & b_{x}-b_{S A}-b_{\mathrm{LA}}-b_{\mathrm{LB}}
\end{aligned}
$$

where

$$
\begin{aligned}
& A_{1}=\beta_{\mathrm{LA}}\left(G_{A}-G_{B} \beta_{2 S A}^{2}\right)-\beta_{\mathrm{SA}}^{-1}\left(G_{A} \beta_{2 S A}^{2}-G_{B} \beta_{2 S B}^{2}\right) D_{1} / D_{3}, \\
& A_{2}=\beta_{\mathrm{LB}}\left(G_{B}-G_{B} \beta_{2 S B}^{2}\right)+\beta_{\mathrm{SA}}^{-1}\left(G_{A} \beta_{2 S A}^{2}-G_{B} \beta_{2 S B}^{2}\right) D_{2} / D_{3}, \\
& A_{3}=G_{B}\left(\beta_{2 S B}^{2}-\beta_{S B} \beta_{\mathrm{LB}}\right)-\left(G_{A}+G_{B} \beta_{S B} \beta_{S A}^{-1}\right) D_{2} / D_{3}, \\
& A_{4}=\left(G_{A} \beta_{2 S A}^{2}+G_{B} \beta_{S B} \beta_{\mathrm{LA}}\right)-\left(G_{A}+G_{B} \beta_{S B} \beta_{S A}^{-1}\right) D_{1} / D_{3}, \\
& A_{5}=G_{B} \beta_{S B} \beta_{S A}^{-1} \\
& A_{6}=\beta_{S A}^{-1}\left(G_{A} \beta_{2 S A}^{2}-G_{B} \beta_{2 S B}^{2}\right), \\
& D_{1}=1+\beta_{S B} \beta_{\mathrm{LA},} \\
& D_{2}=1-\beta_{S B} \beta_{\mathrm{LB}}, \\
& D_{3}=1+\beta_{S B} / \beta_{S A} .
\end{aligned}
$$

If the term $A_{1} A_{3}+A_{2} A_{4}$ in the denominator of the expressions in Equation (A3) is zero, the constants $G$ and $\bar{G}$ become infinite. (These equations are derived in Weertman (2004) and, in equivalent form, in Weertman (1980). The presence of a thin, non-uniform water layer between the two half-spaces $A$ and $B$ will not appreciably affect these equations provided that traction stress can be transmitted across the layer. Only if the bed were perfectly smooth would it not be possible to transmit a shear traction stress.)

Note that the Stoneley velocity is the velocity that satisfies the relationship (Achenbach, 1973; Weertman, 2004):

$$
A_{1} A_{3}+A_{2} A_{4}=0 \text {. }
$$

Bindschadler and others (2003a, b) point out that Blankenship and others (1987) reported a shear wave velocity $\left(C_{S B}\right)$ 
in till (under Whillans Ice Stream) of about $150 \mathrm{~m} \mathrm{~s}^{-1}$ and a longitudinal wave speed $\left(C_{\mathrm{L} B}\right)$ of about $1700 \mathrm{~m} \mathrm{~s}^{-1}$. These velocities require the shear modulus, Poisson's ratio and density for till $\left(G_{B}, \nu_{B}, \rho_{B}\right.$ in Fig. 1$)$ to have the values listed in Table 2 if the till density is assumed to be twice that of ice. In Table 2 are also listed the values for these quantities for ice (Hobbs, 1974, p. 258), and $C_{\mathrm{S} A}$ and $C_{\mathrm{L} A}$ calculated from them. The curves of Figure 2 are calculated using the constants of Table 2 . If the density of till $\left(\rho_{B}\right)$ lies between one and three times the density of ice $\left(\rho_{A}=980 \mathrm{~kg} \mathrm{~m}^{-3}\right)$ it is impossible, according to Equation (A4), for a Stoneley wave to exist at the ice-till interface if till has the wave velocities reported by Blankenship and others.

\section{Transonic dislocation}

When an Eshelby velocity $V_{E}$ exists in the velocity range $V_{\mathrm{S} B}<V_{\mathrm{E}}<V_{\mathrm{L} B}, V_{\mathrm{S} A}, V_{\mathrm{LA}}$ the terms $G, \bar{G}, G^{+}, G^{-}$are given by

$$
\begin{aligned}
G & =2\left(G_{B} / b_{x}\right) b_{\mathrm{L} B} \beta_{\mathrm{L} B}, \\
\bar{G} & =-2\left(G_{B} / b_{x}\right)\left(b_{\mathrm{S} B}+b_{\mathrm{L} B} \beta_{2 \mathrm{~S} B}^{2}\right), \\
G^{+} & =-2\left(G_{A} / b_{x}\right)\left[b_{\mathrm{S} A}+b_{\mathrm{LA} A}\left(2 \beta_{2 \mathrm{LA}}^{2}-\beta_{2 \mathrm{~S} A}^{2}\right)\right], \\
G^{-} & =2\left(G_{B} / b_{x}\right) b_{\mathrm{L} B}\left(2 \beta_{2 \mathrm{~L} B}^{2}-\beta_{2 \mathrm{~S} B}^{2}\right) .
\end{aligned}
$$

The sub-dislocation Burgers vectors are

$$
\begin{aligned}
& b_{\mathrm{LA}}=b_{x} C_{2} /\left(C_{2} D_{6}+C_{1} D_{5}\right), \\
& b_{\mathrm{L} B}=b_{x} C_{1} /\left(C_{2} D_{6}+C_{1} D_{5}\right), \\
& b_{\mathrm{S} A}=b_{x}-b_{\mathrm{LA}}-b_{\mathrm{L} B}, \quad b_{\mathrm{S} B}=0 .
\end{aligned}
$$

Here

$$
\begin{aligned}
C_{1} & =\beta_{\mathrm{LA}} G_{A}\left(1-\beta_{2 \mathrm{~S} A}^{2}\right), \\
C_{2} & =\beta_{\mathrm{L} B}\left(G_{B}-G_{A} \beta_{2 \mathrm{~S} A}^{2}\right), \\
C_{3} & =\left(G_{B} \beta_{2 \mathrm{~S} B}^{2}+\beta_{\mathrm{S} A} \beta_{\mathrm{L} B} G_{A}\right), \\
C_{4} & =G_{A}\left(\beta_{2 \mathrm{~S} A}^{2}-\beta_{\mathrm{S} A} \beta_{\mathrm{L} A}\right), \\
D_{5} & =\left(1+\beta_{\mathrm{S} A} \beta_{\mathrm{LB} B}\right), \\
D_{6} & =\left(1-\beta_{\mathrm{S} A} \beta_{\mathrm{L} A}\right) .
\end{aligned}
$$

The Eshelby velocity is given by

$$
C_{1} C_{3}+C_{2} C_{4}=0
$$

\section{APPENDIX B \\ BASAL WATER}

In my review article on basal water flow (Weertman, 1972) it was pointed out that the pressure gradient driving basal water into or away from a Röthlisberger (R) tunnel depends upon the power-law creep exponent $n$. If $n>2$, water is driven into the $\mathrm{R}$ tunnel. If $n<2$, water flows away from the tunnel. In that article it was pointed out that if a large shear stress exists at the bottom of the ice mass the effective value of $n$ is reduced from Glen's value of $n \approx 3$ to a value of $n \approx 1$. There is always a radial distance from an $\mathrm{R}$ tunnel beyond which $n \approx 1$ and water cannot flow to an $\mathrm{R}$ channel. The basal shear stress, of course, is small under the ice plain (1 kPa; Bindschadler and others, 2003b) and should not cause $\mathrm{R}$ tunnels to leak the water. The longitudinal stress $\sigma_{x x}$, however, within the ice of the ice plain should be about the same as that in a floating ice shelf of similar thickness, that is, of order $(1 / 2) \rho_{\text {ice }} g H\left(1-\rho_{\text {ice }} / \rho_{\text {sea water }}\right)$ where the terms have their usual meaning. Thus $\sigma_{x x} \approx$ $110-180 \mathrm{kPa}$ for an ice thickness of $H \approx 300-500 \mathrm{~m}$. These values are high enough to make it difficult for most $\mathrm{R}$ tunnels to remain in existence under an ice plain. Thus the base of an ice plain, if it is melting, should have a broadly distributed, lubricating water layer (of variable thickness). (The anonymous reviewer points out that the Whillans Ice Plain experiences longitudinal compression and lateral extension. The argument above is not changed provided the stress levels remain at about the same magnitude.)

\section{Surge mechanism}

The tensile stress mechanism above might also cause exceptional lubrication of a surging glacier. Surging glaciers elongate at a rate of the order of $0.1 \mathrm{a}^{-1}$. This strain would require $\sigma_{x x}$ to have a value of the order of $140 \mathrm{kPa}$. This longitudinal stress could lead too to a water layer (film) of variable but sufficient thickness to allow fast surge sliding motion. 